\section{Predictive molecular markers for EGFR-TKI in non-small cell lung cancer patients: new insights and critical aspects}

\section{Paola Ulivi, Daniele Calistri, Wainer Zoli,} Dino Amadori

Istituto Scientifico Romagnolo per lo Studio e la Cura dei Tumori (I.R.S.T.), Meldola, Italy

\section{Abstract}

In recent years, a number of novel agents have been investigated that target specific molecular pathways in non-small cell lung cancer (NSCLC). A great deal of effort has been focused on identifying specific markers that predict treatment response, given that a tailored approach would maximize both the therapeutic index and the cost-effectiveness. The epidermal growth factor receptor (EGFR) pathway has emerged as a key regulator of cancer cell proliferation and invasion, and several specific EGFR inhibitors have been examined. Gefitinib and erlotinib are selective EGFR tyrosine kinase inhibitors (EGFR-TKIs), demonstrating good results in selected cases both in terms of objective response rate and of overall survival. At present, EGFR gene mutations are the best positive predictive factors for TKI therapy, and a number of other potential biomarkers are being investigated as additional positive or negative predictors of response. The correct selection of patients that could benefit from these innovative therapies, based on an accurate molecular characterization, is mandatory to provide the best clinical management. Currently, the main factor limiting the characterization of metastatic NSCLC patients is the small quantity of tumor cells available for molecular analysis. In this paper we provide an overview of the most important molecular predictive markers for EGFR-TKIs therapy in NSCLC patients, and focus attention on biological samples suitable for analysis and alternative sampling approaches such as plasma- or serum-derived DNA.

\section{Introduction}

The epidermal growth factor receptor (EGFR) signaling pathway has emerged as a key signal transduction pathway in promoting cancer cell proliferation and tumor invasion. EGFR is normally found on the surface of epithelial cells and its overexpression is commonly observed in several malignancies including lung cancer. ${ }^{1,2}$ The tyrosine kinase domain of EGFR consists of an $\mathrm{N}$ - and a C-lobe, with ATP binding to the cleft formed between these two lobes. Activation by specific ligands or mutations leads to homodimer and heterodimer formation (with other members of the ERBB protein family). Dimerization consequently stimulates intrinsic EGFR tyrosine kinase activity and triggers autophosphorylation of specific tyrosine residues within the cytoplasmic regulatory domain. ${ }^{3}$ Several signal transducers are then activated that initiate multiple signaling pathways, including mitogen-activated protein kinase (MAPK), phosphatidylinositol 3-kinase/AKT, and the signal transducer and activator of transcription (STAT) 3 and STAT5 pathways. All these events trigger an increase in cell proliferation, migration, metastatization, angiogenesis, and evasion of apoptosis (Figure 1).

Inhibition of the EGFR pathway with tyrosine kinase inhibitors (TKIs) has proven to be an effective treatment strategy for advanced non-small cell lung cancer (NSCLC). ${ }^{46}$ TKIs are a class of drugs that act on the EGFR ATP-binding site, leading to the reversible blocking of downstream signaling pathway activation. In view of results reported by the IPASS study, gefitinib (IRESSA, AstraZeneca Pharmaceuticals, Wilmington, DE, USA) was the first TKI approved by the European Medicines Agency (EMEA) for all lines of therapy in adults with locally advanced or metastatic NSCLC with activating EGFR tyrosine kinase mutations. Erlotinib was the next TKI to be developed (TARCEVA, Genentech, Inc, South San Francisco, and OSI Pharmaceuticals, Inc, Melville, NY, USA), receiving FDA approval for salvage use in unselected patients with locally advanced or metastatic NSCLC who had progressed after standard chemotherapy. Despite the fact that these drugs act specifically on EGFR, there is no direct correlation between receptor expression and therapeutic drug efficacy. Indeed, many EGFR-positive tumors do not respond to EGFR TKI therapy, while a large number of EGFR-negative tumors have been reported to respond. ${ }^{8.11}$ Moreover, although EGFR mutation status is the best predictor of response to TKIs, many NSCLC EGFR mutated patients do not respond. ${ }^{12}$ For this reason, a number of alternative predictive markers are currently under investigation.

In this review we focus on the most promising predictive markers for EGFR-TKIs, and discuss how this knowledge could help to improve treatment approaches. We also consider the correlation between primary tumor and metastatic lesion alterations, and discuss other biological samples suitable for the study of predictive markers, with particular attention on those obtained from non-invasive procedures such as plasma or serum-derived DNA.
Correspondence: Wainer Zoli, Istituto Scientifico Romagnolo per lo Studio e la Cura dei Tumori (I.R.S.T.), via Maroncelli 40, 47014 Meldola (FC), Italy. E-mail:w.zoli@ausl.fo.it

Key words: non-small cell lung cancer, epidermal growth factor receptor- tyrosine kinase inhibitors, plasma/ serum, predictive markers.

Contributions: PU, substantial contributions to conception and design, acquisition of data, analysis and interpretation of data, drafting the article, revising it critically for important intellectual content and final approval of the version to be published; DC and WZ, drafting the article, revising it critically for important intellectual content and final approval of the version to be published. DA, final approval of the version to be published.

Acknowledgements: the authors would like to thank Dr. Ian Seymour for help with editing the manuscript.

Conflict of interest: the authors report no conflicts of interest.

Received for publication: 13 April 2010.

Revision received: 4 June 2010.

Accepted for publication: 8 June 2010 .

This work is licensed under a Creative Commons Attribution 3.0 License (by-nc 3.0).

(C) Copyright P. Ulivi et al., 2010

Licensee PAGEPress, Italy

Journal of Nucleic Acids Investigation 2010; 1:e10 doi:10.4081/jnai.2010.e10

\section{Predictors of response to tyrosine kinase inhibitors}

\section{Epidermal growth factor receptor \\ overexpression}

EGFR protein expression, evaluated by immunohistochemistry (IHC), was the first putative predictive marker to be retrospectively explored in EGFR-TKI-treated NSCLC patients. Several studies have reported no correlation between EGFR levels and response to gefitinib or erlotinib. ${ }^{8.11}$ Conversely, two other studies have suggested that EGFR IHC assessment could help to identify a subset of patients achieving survival improvement. ${ }^{13-15}$ In the BR21 trial, individuals with high EGFR expression were associated with response to erlotinib $(\mathrm{P}=0.03)$. The univariate analysis showed a significant overall survival (OS) advantage of erlotinib compared with placebo in IHC-positive patients (HR, 0.68 (95\% $\mathrm{CI}, 0.49-0.95) ; \mathrm{P}=0.02$ ), but not in IHC-negative cases (HR, 0.93 (95\% CI, 0.63-1.36); $\mathrm{P}=0.70$ ). However, the multivariate analysis did not reveal any correlation between EGFR expression and survival. ${ }^{13,16}$ These conflicting results, together with the availability of many different commer- 
cial anti-EGFR antibodies, indicate that IHC may not be the best method to determine a patient's eligibility to receive EGFR TKI therapy.

\section{Epidermal growth factor receptor copy number}

High EGFR gene copy number (amplification or high polisomy), using fluorescent in situ hybridization (FISH), has been detected in approximately $30 \%$ of NSCLC patients, and is usually associated with poor clinical outcome. ${ }^{17}$ Furthermore, significant survival benefits have been observed in EGFR FISH-positive patients treated with EGFR-TKIs in both phase II $^{14,17}$ and phase III ${ }^{13,15}$ trials. In the ISEL trial, a double-blind randomized phase III study evaluating the efficacy of gefitinib in 1,692 individuals with locally advanced or metastatic NSCLC, high EGFR copy number was associated with a significantly longer OS than low copy number $(\mathrm{P}=0.045)$. Moreover, high EGFR copy number patients treated with gefitinib were associated with a $39 \%$ lower risk of death than those receiving placebo. ${ }^{15}$ Response rates (RR) and time to progression (TTP) were also improved in high EGFR copy number patients treated with EGFR-TKI, although these results have not been demonstrated in other published studies (Table 1). In contrast, in the study by Crinò et al. ${ }^{28}$ individuals receiving gefitinib, with EGFR FISH-positive tumors, appeared to have poorer outcomes than those with EGFR-FISH-negative tumors. Moreover, individuals who were EGFR-FISH-positive benefited more from vinorelbine than from gefitinib, although the latter showed an improved toxicity profile.

\section{Somatic epidermal growth factor receptor mutations}

In 2004, three different research groups showed that EGFR TK domain mutations are associated with the response of NSCLC patients to gefitinib ${ }^{29.31}$ or erlotinib. ${ }^{31}$ Somatic mutations were more frequently observed in patients with features known to be associated with TKI sensitivity, such as female gender, adenocarcinoma histology, Asian ethnicity, and no smoking history ("never smokers"). Following these initial observations, the majority of EGFR mutations have been report- ed to be found in the first four TK domain exons $^{32-37}$ (Figure 2). The most common EGFRsensitizing mutations, accounting for $85-90 \%$ of all those found in NSCLC, include the exon 19 deletion (loss of codons 746-750, ELREA amino acid sequence) and the exon 21 L858R substitution. Both mutations have been shown to enhance EGFR kinase activity and activate its downstream signaling, playing a pivotal role in NSCLC cell survival. ${ }^{30,38}$ EGFR-TKIs are thought to neutralize the excessive survival signals that cancer cells are "addicted to", leading to dramatic apoptosis..$^{38,39}$ Moreover,

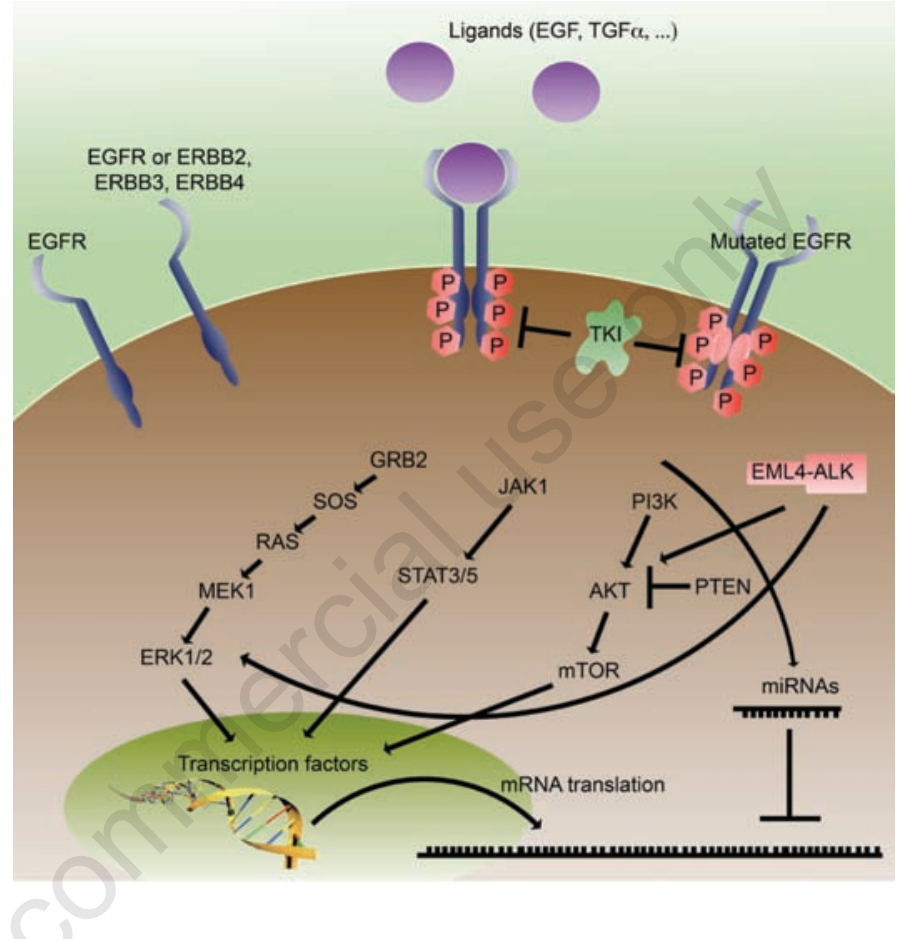

Figure 1. Epidermal growth factor receptor and ERBB proteins and their downstream pathways.

Table 1. Clinical parameters of patients treated with tyrosine kinase inhibitors as a function of epidermal growth factor receptor alterations.

\begin{tabular}{|c|c|c|c|c|c|c|c|c|c|}
\hline \multirow[t]{2}{*}{ Ref. } & \multicolumn{3}{|c|}{ EGFR gene gain ${ }^{\circ}$} & \multicolumn{5}{|c|}{ EGFR mut } & \multirow{2}{*}{$\begin{array}{l}\text { Gene gain/mut } \\
\text { correlation }\end{array}$} \\
\hline & $\begin{array}{c}\text { EGFR } \\
\text { gene gain/ } \\
\text { total pts (\%) }\end{array}$ & $\begin{array}{l}\text { RR\% } \\
\text { gene gain/ } \\
\text { no gain }\end{array}$ & $\begin{array}{l}\text { TTP (mos) } \\
\text { gene gain/ } \\
\text { no gain }\end{array}$ & $\begin{array}{l}\text { OS (mos) } \\
\text { gene gain/ } \\
\text { no gain }\end{array}$ & $\begin{array}{l}\text { EGFR mut/ } \\
\text { total pts (\%) }\end{array}$ & $\begin{array}{l}\mathbf{R R} \% \\
\mathrm{mut} / \mathrm{wt}\end{array}$ & $\begin{array}{l}\text { TTP (mos) } \\
\text { mut/wt }\end{array}$ & $\begin{array}{l}\text { OS (mos) } \\
\text { mut/wt }\end{array}$ & \\
\hline Takano, $2005^{20}$ & 29/66 (44\%) & $72 / 38$ & $9.4 / 2.6$ & - & $39 / 66(59 \%)$ & $82 / 11$ & $12.6 / 1.7$ & $20.4 / 6.9$ & YES $(\mathrm{P}<0.001)$ \\
\hline Bell, $2005^{21}$ & $7 / 90(8 \%)$ & $29 / 15$ & - & - & $14 / 79(18 \%)$ & $46 / 10$ & $3.8 / 1.9$ & ND & NO \\
\hline Sone, $2007^{22}$ & $26 / 54(48 \%)$ & $30.8 / 21.4$ & ND & ND & $17 / 59(29 \%)$ & $59 / 14$ & $7.3 / 1.8$ & $18.9 / 6.4$ & NO \\
\hline Cappuzzo, $2007^{23}$ & $25 / 36(69 \%)$ & $\begin{array}{c}68 / 9.1 \\
74 / 9.1^{+}\end{array}$ & $7.6 / 2.7$ & $\mathrm{NR} / 7.4$ & $24 / 37(65 \%)$ & $63 / 23$ & $3.8 / 3.1$ & $\mathrm{NR} / 11.1$ & YES $(\mathrm{P}<0.005)$ \\
\hline Hirsch, $2006^{15}$ & $114 / 370(31 \%)$ & $16.4 / 3.2$ & $4.5 / 2.4$ & $8.3 / 4.3$ & $26 / 215(12 \%)$ & $37.5 / 2.6$ & $\begin{array}{c}\text { Not } \\
\text { evaluable }\end{array}$ & $\begin{array}{c}\text { Not } \\
\text { evaluable }\end{array}$ & YES $(\mathrm{P}<0.05)$ \\
\hline Hirsch, $2007^{24}$ & $59 / 183(32 \%)$ & $33 / 6$ & $9 / 3$ & $18 / 8$ & 43/157 (27\%) & $39 / 7$ & $3 / 3$ & $13 / 11$ & YES $(P<0.05)$ \\
\hline Miller, $2008^{12}$ & $24 / 76(32 \%)$ & $43 / 13$ & $9 / 2$ & $25 / 16$ & $18 / 81(22 \%)$ & $83 / 7$ & $13 / 2$ & $23 / 17$ & - \\
\hline Ahn, $2008^{25}$ & $36 / 88(40.9 \%)$ & 41.7/17.3 & $5.8 / 1.8$ & NR/10.1 & $25 / 92(27 \%)$ & $58 / 16$ & $8.6 / 2.5$ & $\mathrm{NR} / 10.8$ & YES $(\mathrm{P}<0.05)$ \\
\hline Dongiovanni, $2008^{26}$ & $17 / 43(40 \%)$ & $79 / 7$ & 14.1/2.3 & $15.7 / 5.2$ & $9 / 43(21 \%)$ & $100 / 12$ & $14.9 / 2.4$ & $16.4 / 5.0$ & YES \\
\hline Schneider, $2008^{27}$ & $49 / 208(24 \%)$ & $17.1 / 5.8$ & $5.7 / 2.3^{*}$ & $8.6 / 6.1$ & $6 / 92(7 \%)$ & $50 / 2.9$ & $12.9 / 2.3^{*}$ & $16.8 / 5^{*}$ & - \\
\hline
\end{tabular}

EGFR: epidermal growth factor receptor; RR: response rate; TTP: time to progression: OS: overall survival; pts: patients; ND: no differences; NR: not reached; mut: mutant; wt: wild type. ${ }^{\circ}$ Evaluated by FISH (except for references 12,25$) ;{ }^{+}$refers to no smokers; ${ }^{*}$ interpolated by survival curves. 


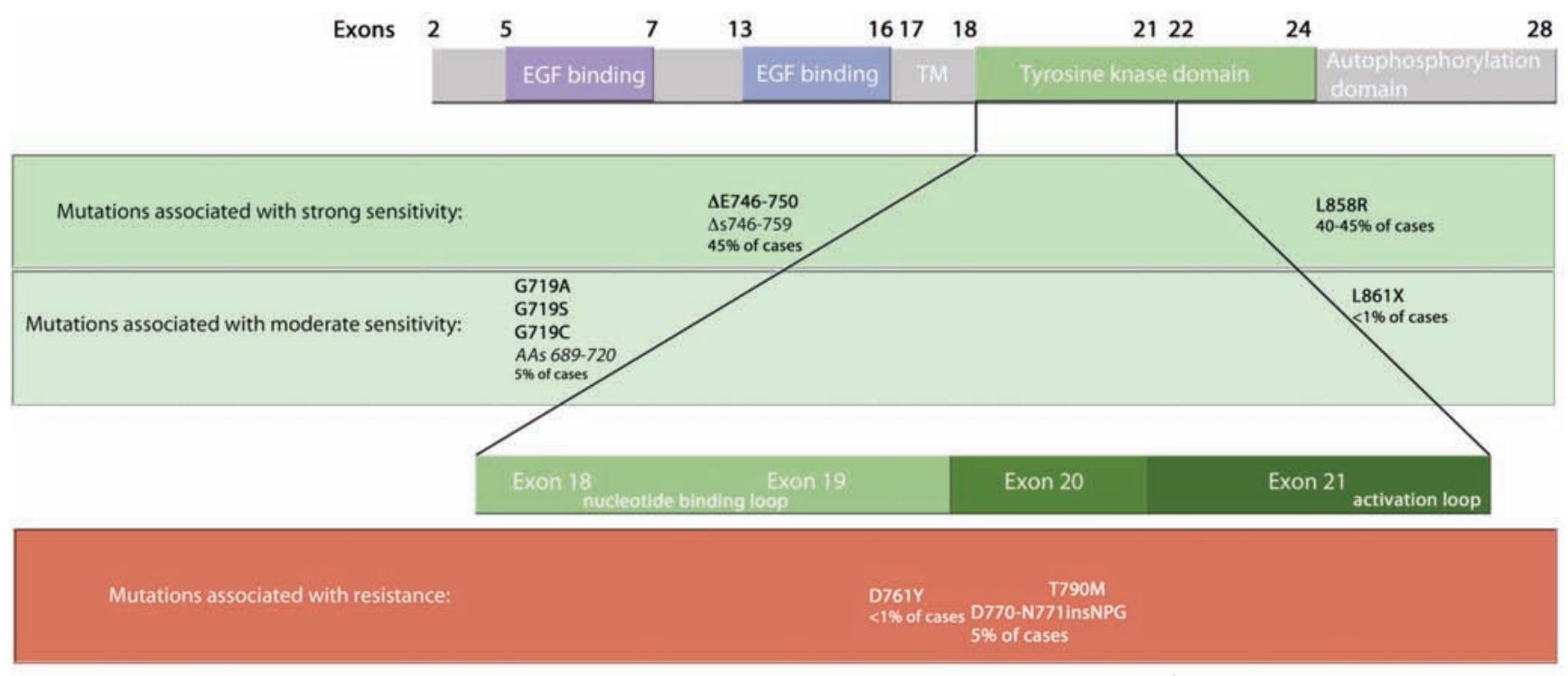

Figure 2. Schematic figure of EGFR mutations reported in NSCLC. The principal mutations are located in exons 18-21, in the tyrosine kinase domain. Mutations associated with sensitivity and resistance are represented in green and orange, respectively. In frame deletions of exon 19 and the exon 21 point mutation (L858R) are the most frequent alterations, accounting for 85-90\% of $E$ GFR mutations. Nucleotide substitutions in exon 18, in particular G719C and G719S account for a further 5\% of EGFR mutations, and alterations in exon 20 for another $5 \%$.

activating EGFR mutations have also been shown to enhance gefitinib affinity by increasing its activity. ${ }^{40}$ Point mutations in exon 18 (G719A/C) occur in about 5\% of cases, are associated with oncogenic potential in both cell culture and transgenic mouse studies, ${ }^{32,36,41}$ and are also correlated with moderate TKI sensitivity. ${ }^{41,42}$ A large number of studies have reported a significantly higher overall response rate (ORR $>80 \%), O S$ and time to progression (TTP) in patients with activating EGFR mutations compared to wild-type individuals (ORR <10\%) (Table 1).

EGFR kinase domain mutations have also been associated with acquired resistance to EGFR TKI, approximately $50 \%$ of cases being explained by the presence of a secondary mutation involving the methionine to threonine substitution in codon 790 (T790M) of exon $20 .{ }^{44.46}$ However, although the presence of T790M does not preclude a response to EGFR TKI, it is associated with significantly shorter progression free survival (PFS) compared to wild-type patients (7.7 vs. $16.5 ; \mathrm{P}<0.001){ }^{47}$ Recently, a novel, irreversible covalent pyrimidine inhibitor that is specific for T790M has shown promising results, underlining the importance of the strategy to identify new classes of mutant-selective kinase inhibitors. ${ }^{48}$ Other less common mutations conferring modest resistance to EGFR-TKIs include the D761Y substitution and insertions in exon 20. ${ }^{49,50}$ Somatic mutations have frequently been correlated with high EGFR copy number, but supporting data on this point are still discordant (Table 1).

\section{KRAS mutations}

ERBB signaling pathways include downstream GTPases encoded by RAS genes. It has been estimated that $15-30 \%$ of lung adenocarcinomas contain activating mutations in the RAS family member, KRAS, most of which are found in codons 12 and 13 in exon $2 .^{51,52}$ As a rule, EGFR and KRAS mutations are mutually exclusive, and, furthermore, it has been suggested that activation of either the EGFR or RAS signaling pathways has similar effects on lung tumorigenesis. ${ }^{34}$ Moreover, EGFR mutations are common in tumors from patients who have smoked less than 100 cigarettes in their lifetime ("never smokers"), ${ }^{26}$ while KRAS mutations more frequently occur in individuals with a history of substantial cigarette use..$^{53}$

The presence of KRAS mutations is associated with resistance to EGFR-TKI treatment, ${ }^{54.56}$ probably due to the fact that constitutive activation of the pathway by mutated KRAS neutralizes the inhibitory effects exerted by EGFR inhibition. However, a recent report by Jackman et al. ${ }^{57}$ demonstrated no apparent difference in survival between KRAS mutant/EGFR wild-type and KRAS wildtype/EGFR wild-type NSCLC patients. Furthermore, considering the mutually exclusive nature of KRAS and EGFR mutations, the presence of a $K R A S$ mutation merely indicates the absence of an EGFR mutation, the main predictor of sensitivity. Taking these considerations into account, the clinical usefulness of $K R A S$ mutations as a selective marker for EGFR-TKI sensitivity in NSCLC appears to be limited.

\section{MET}

MET is a high affinity tyrosine kinase receptor for hepatocyte growth factor (HGF). Interaction with its ligand has been shown to induce autophosphorylation at multiple tyrosine residues, activating downstream pathways involved in cell growth, motility, survival, invasion and metastasis. ${ }^{58}$ MET amplification has been observed in about $10-20 \%$ of NSCLC cases and is associated with shorter survival. $^{59,60}$ Moreover, high MET copy number seems to correlate with shorter time to treatment failure in patients with gefitinib-sensitive activating EGFR mutations, ${ }^{61}$ although these results have not been confirmed in other studies. ${ }^{62}$ An increase in MET gene copy number is also reported to be a mechanism of acquired EGFR-TKI resistance, by driving ERBB3-dependent activation of PI3K, allowing tumor cells to bypass the activated mutant EGFR pathway. ${ }^{63,64}$ Furthermore, the acquired resistance due to $M E T$ amplification seems to occur independently of the T790M alteration..$^{65}$ For these reasons, combination therapies with MET and EGFR kinase inhibitors should be considered for patients whose tumors have become resistant to gefitinib or erlotinib. ${ }^{62,65}$

\section{EML4-ALK}

The EML4-ALK fusion oncogene is one of the most recently identified molecular targets for the treatment of NSCLC. Consisting of a chimeric tyrosine kinase, the N-terminal of echinodermal microtubule associated proteinlike 4 (EML4) is fused to the intracellular kinase domain of anaplastic lymphoma kinase 
(ALK) ${ }^{66}$ and the resulting fusion protein has shown oncogenic activity in both in vitro and in vivo models. ${ }^{67,68}$ The frequency of this rearrangement is very low in NSCLC patients, about $6.7 \%$, and is more common in young, never/light smokers with adenocarcinoma. In addition, the presence of EMLA-ALK is strongly associated with resistance to EGFR-TKIs and sensitivity to ALK inhibitors. ${ }^{69}$ Promising results have been achieved in a phase I study using the oral ALK inhibitor PF02341066 with FISH-detected ALK rearrangements, representing a new therapeutic target for this molecularly-defined subset of NSCLC patients. ${ }^{70}$

\section{p-AKT}

AKT, a downstream mediator of phosphatidylinositol 3-kinase (PI3K), is a signal transduction protein that plays a central role in tumorigenesis. ${ }^{71}$ Moreover its overexpression has been shown to confer resistance to chemotherapy and radiation. ${ }^{72}$ AKT is activated by PI3K, and it can be dysregulated because of frequent inactivation of the phosphatase and tensin homolog deleted on chromosome 10 (PTEN) tumor suppressor gene, which negatively regulates PI3K levels. ${ }^{73}$ PhosphorylatedAKT has been reported to be expressed in lung cancers and it is correlated with a better response to gefitinib, EGFR gene gain and protein expression. ${ }^{14,74}$ In other studies, p-AKT expression has not shown a correlation with a better outcome of patients to EGFR-TKI. ${ }^{15}$ Conversely, PTEN loss, and subsequent p-AKT activation, has been associated with EGFRTKIs resistance, by decreasing cell apoptosis. ${ }^{75}$

\section{MicroRNAs}

MicroRNAs (miRNAs) are a new class of non-coding RNAs of 21-25 nucleotides implicated in cancer biology. MiRNAs post-transcriptionally regulate gene expression by binding to complementary sequences in the 3 ' untranslated region (3' UTR) of target messenger RNAs (mRNAs) ${ }^{76}$ suppressing protein translation and downregulating protein expression. ${ }^{77}$ MiRNA deregulation is fast becoming an important area of study in carcinogenesis because it can drastically influence cell physiology. ${ }^{78}$ Some miRNAs, for example miR-21, have been shown to be more highly expressed in patients with EGFR mutations than in those without. ${ }^{79}$ It has been hypothesized that aberrant miR-21 expression might contribute to lung cancer development in "never smokers" through EGFR signaling pathway activation, and that miR-21 silencing might enhance EGFR-TKI induced apoptosis. In addition, miR-128b seems to be directly implicated in EGFR regulation. In particular, miR-128b loss of heterozygosity is frequently found in tumors and correlates significantly with clinical response and survival following gefitinib treatment. ${ }^{80}$ The identification of miRNA oncogene regulators could therefore have far-reaching implications for lung cancer treatment, including improved patient selection for targeted agents, and the development of novel therapeutics and early disease biomarkers.

\section{Multivariate approaches}

Some studies have tried to identify specific gene expression profiles able to discriminate between patients responsive or not to EGFRTKIs. It has been demonstrated that a gene expression signature of 180 genes has sufficient robustness and accuracy to predict sensitivity, both in cell lines and in lung adenocarcinomas. ${ }^{81}$ Other studies have identified specific serum proteomic profiles able to distinguish between EGFR-TKI sensitive or resistant patients. ${ }^{82,83}$ In the paper by Carbone et al., a protein expression profile was identified that is able to discriminate patients treated with bevacizumab and erlotinib that have a good or poor prognosis. Median OS of 61 and 24 weeks, and median PFS of 36 and eight weeks, were reported in the good and poor prognosis groups, respectively. ${ }^{82}$ These studies have highlighted the possibility of multiparametric approaches, encompassing many members of the EGFR signaling cascade.

\section{Correlation between primary tumor and metastases alterations}

Although there is a clear and consolidated need to screen NSCLC patients for EGFR mutations, the best type of biological sample for this characterization has not yet been elucidated. Recent experience in colorectal cancer has established that KRAS mutations in the primary tumor and the metastatic lesions are identical, ${ }^{84,85}$ simplifying patient characterization for cetuximab treatment. Conversely, lung cancer studies have demonstrated substantial differences between primary and metastatic sites. Moreover, the vast majority of studies have only reported EGFR status in the primary tumor even though the main targets of NSCLC therapy are the metastases themselves. Italiano et al. ${ }^{86}$ were the first group to question the stability of EGFR expression during the NSCLC metastatic process. EGFR status, confirmed by IHC and FISH, was found to vary significantly between primary NSCLC and distant metastasis. Subsequent studies have confirmed these results, in particular for lung cancer brain metastases.$^{87,88}$ Further investigations have extended this analysis to other downstream signaling pathway markers, such as phosphorylated Akt and MAPK, ${ }^{89}$ ERCC1,

\section{VEGFR and Ki67. ${ }^{90}$}

There is no shortage of evidence supporting the discordance in EGFR and KRAS mutations between primary tumors and the corresponding metastases. ${ }^{91-96}$ In the study by Schmid et al. on 96 paired samples of primary lung adenocarcinoma and corresponding locoregional lymph node metastases, a correspondence of EGFR and KRAS alterations in the two biological samples was observed in $14 \%$ and $31 \%$ of patients, respectively, demonstrating a substantial discordance between metastases and primary tumor that may be important for the selection of patients for EGFR-TKI therapy. ${ }^{95}$ Similarly, Monaco et al. ${ }^{96}$ demonstrated a substantial discordance in KRAS mutations between the primary tumor and corresponding synchronous or metachronous metastases, with a concordance of $18 \%$, whereas no EGFR mutations were found. The mechanism by which metastases arise with different profiles from the primary tumor is still unclear, but the possibility of heterogeneous tumor populations, genetic drift, or clonal selection of tumor clones, may exist. Ultimately, these results advocate molecular testing for metastatic lesions in addition to, or in lieu of the primary tumors, in view of the fact that the main aim of advanced NSCLC treatment is to attack the metastatic cells.

\section{Biological samples suitable for molecular characterization}

Another important point to consider in the molecular characterization of NSCLC patients is to provide sufficient sampling materials that are not always available for inoperable stage IIIB and IV tumors. Although frozen specimens are the preferred source for EGFR and KRAS analysis, ${ }^{97}$ mutation testing is regularly carried out on Formalin-Fixed, Paraffin-Embedded (FFPE) specimens obtained from surgery for resectable tumors, and from biopsy for advanced tumors.

About one-third of primary NSCLC diagnoses are performed on cytological samples, and usually no other biopsy materials are available for molecular analyses. Effort has, therefore, been focused on detecting EGFR mutations in cytological samples. Results from several studies have shown that, after destaining of cytological slides, extracted DNA is of sufficient quality for analysis..$^{98-100}$

Transesophageal ultrasound-guided fine needle aspiration (EUS-FNA) has proven to be a useful method for NSCLC staging and diagnosis. ${ }^{101}$ Recently, in our laboratory, we have successfully used this methodology to obtain fresh lymph node material suitable for DNA extraction and EGFR analysis (P Ulivi et al., unpublished data, 2009). However, the macro- 
Table 2. Correlation between EGFR mutation status in paired plasma and tumor samples.

\begin{tabular}{|c|c|c|c|c|}
\hline Ref. & N. EGFR-mutated tumors & Biological material & Methodology & Mutations in paired samples (\%) \\
\hline Kimura, $2007^{105}$ & 8 & Serum & SARMS & 6/8 (75\%) \\
\hline Maheswaran, $2008^{47}$ & 18 & $\begin{array}{c}\text { Plasma } \\
\text { CTC }\end{array}$ & $\begin{array}{l}\text { SARMS } \\
\text { SARMS }\end{array}$ & $\begin{array}{c}7 / 18(39 \%) \\
17 / 18(94 \%)\end{array}$ \\
\hline Yung, 2009 106 & 12 & Plasma & Digital PCR & $11 / 12(92 \%)$ \\
\hline Kuang, $2009^{107}$ & 30 & Plasma & SARMS and WAVE/Surveyor & $21 / 30(70 \%)$ \\
\hline $\mathrm{He}, 2009^{108}$ & 18 & Plasma & Mutant-enriched PCR & 17/18 (94.4\%) \\
\hline Bai, $2009^{109}$ & 77 & Plasma & DHPLC & $63 / 77(82 \%)$ \\
\hline Mack, $2009^{110}$ & 7 & Plasma & SARMS & $5 / 7(71 \%)$ \\
\hline
\end{tabular}

CTC: circulating Tumor cells; SARMS: scorpion amplification refractory mutation system; DHPLC: denaturing high-performance liquid chromatography.

selection of tumor cells from fresh EUS-FNA samples cannot be performed, and so the lack of a mutation could indicate either a real absence or an insufficient number of cells in the starting material.

A non-invasive approach able to overcome the scarcity of tumor material is the analysis of DNA extracted from plasma/serum or from circulating tumor cells (CTC). It has recently been demonstrated that free-tumor derived DNA levels in plasma or serum are significantly higher in lung cancer patients compared to healthy donors. ${ }^{102,103}$ This could be explained by the presence of necrotic cells sloughed from primary tumor or circulating tumor cells, which possess the same genetic lesions.

Kimura et al. were the first group to report on the detection of EGFR mutations in serum. ${ }^{104,105}$ In the 42 patients analyzed, EGFR mutations were detected in 8 tumor samples and in 7 serum samples (one of the serum positive cases was not mutated in the corresponding tumor), demonstrating a high concordance between tumor and serum. ${ }^{105}$ Subsequent studies have attempted to confirm these results in larger case series. ${ }^{106-112}$ Indeed, using a range of different methodologies, serum/plasma EGFR mutations have been reported in over $70 \%$ of patients in which the tumor tissue showed the same mutation (Table 2).

However, in some of these studies, EGFR mutations were found in the plasma but not in the corresponding tumor tissue. In the study of Bay et al. ${ }^{109}$ consisting of 77 patients with primary tumor EGFR mutations, 63 reported identical alterations in the matched plasma. Moreover, $7 \%$ of patients with plasma mutations had no detectable alterations in the corresponding primary tumors and, similarly, $6 \%$ of patients with tumor mutations had no detectable EGFR alterations in the corresponding plasma. The authors tried to explain this apparent inconsistency in terms of the heterogeneity of genetic tumor abnormalities, in which tumoral cells may or may not carry the mutation. The lower tumor cell content in some of the samples may also contribute to the lack of detectable mutations in some tumor tissues in which the corresponding plasma was mutated. The only study reporting a low plasma EGFR mutation frequency is that of Maheswaran et al. ${ }^{47}$ with a sensitivity in plasma and CTC of $34 \%$ and $94 \%$, respectively. Plasma DNA analysis has also be used to monitor patients during gefitinib treatment, for example to characterize secondary mutations, such as the T790M alteration. ${ }^{107}$ Nevertheless, the scarcity of materials obtained from the primary tumor tissue of advanced-stage lung cancer patients and from biopsy or cytological samples, highlights the potential clinical importance of plasma/serum as a surrogate tissue for genetic analysis.

\section{Conclusions}

To date, specific EGFR mutations are the only alterations strongly correlated with tumor response to EGFR-TKIs. Clearly, more studies are necessary to investigate the potential role of other promising predictive markers, such as miRNA. The scarcity of tumor samples and the poor correlation between primary and metastatic lesions represent a major problem for the molecular characterization of patients to decide the best therapeutic strategy. In view of the fact that the main goal of advanced NSCLC therapy is to treat the metastasis, analysis should be focused on the metastatic lesions. Moreover, improvements in the analysis of biological fluids such as plasma or serum could represent an important strategy to overcome these problems.

\section{References}

1. Arteaga CL. Overview of epidermal growth factor receptor biology and its role as a therapeutic target in human neoplasia. Semin Oncol 2002;29:3-9.

2. Hirsch FR, Varella-Garcia M, Bunn PA Jr, et al. Epidermal growth factor receptor in non-small-cell lung carcinomas: correlation between gene copy number and pro- tein expression and impact on prognosis. J Clin Oncol 2003;21:3798-807.

3. Mitsudomi T, Yatabe Y. Epidermal growth factor receptor in relation to tumor development: EGFR gene and cancer. FEBS J 2010;277:301-8.

4. Scagliotti GV. Potential role of multi-targeted tyrosine kinase inhibitors in nonsmall-cell lung cancer. Ann Oncol 2007;18:32-41.

5. Gettinger S. Targeted therapy in advanced non-small-cell lung cancer. Semin Respir Crit Care Med 2008;29:291-301.

6. Rosell R, Viteri S, Molina MA, et al. Epidermal growth factor receptor tyrosine kinase inhibitors as first-line treatment in advanced nonsmall-cell lung cancer. Curr Opin Oncol 2010;22:112-20.

7. Mok TS, Wu YL, Thongprasert S, et al. Gefitinib or carboplatin-paclitaxel in pulmonary adenocarcinoma. N Engl J Med 2009;361:947-57.

8. Kim KS, Jeong JY, Kim YC, et al. Predictors of the response to gefitinib in refractory non-small cell lung cancer. Clin Cancer Res. 2005;11:2244-51.

9. Helfrich BA, Raben D, Varella-Garcia M, et al. Antitumor activity of the epidermal growth factor receptor (EGFR) tyrosine kinase inhibitor gefitinib (ZD1839, Iressa) in non-small cell lung cancer cell lines correlates with gene copy number and EGFR mutations but not EGFR protein levels. Clin Cancer Res 2006;12:7117-25.

10. Dziadziuszko R, Holm B, Skov BG, et al. Epidermal growth factor receptor gene copy number and protein level are not associated with outcome of non-small-cell lung cancer patients treated with chemotherapy. Ann Oncol 2007;18:447-52.

11. Parra HS, Cavina R, Latteri F, et al. Analysis of epidermal growth factor receptor expression as a predictive factor for response to gefitinib ('Iressa', ZD1839) in non-small-cell lung cancer. $\mathrm{Br}$ J Cancer 2004;91:208-12.

12. Miller VA, Riely GJ, Zakowski MF, et al. Molecular characteristics of bronchioloalveolar carcinoma and adenocarcino- 
ma, bronchioloalveolar carcinoma subtype, predict response to erlotinib. J Clin Oncol 2008;26:1472-8.

13. Tsao MS, Sakurada A, Cutz JC, et al. Erlotinib in lung cancer - molecular and clinical predictors of outcome. $\mathrm{N}$ Engl $\mathrm{J}$ Med 2005;353:133-44.

14. Cappuzzo F, Hirsch FR, Rossi E, et al. Epidermal growth factor receptor gene and protein and gefitinib sensitivity in non-small-cell lung cancer. J Natl Cancer Inst 2005;97:643-55.

15. Hirsch FR, Varella-Garcia M, Bunn PA Jr, et al. Molecular predictors of outcome with gefitinib in a phase III placebo-controlled study in advanced non-small-cell lung cancer. J Clin Oncol 2006;24:5034-42.

16. Hirsch FR, Varella-Garcia M, Cappuzzo F. Predictive value of EGFR and HER2 overexpression in advanced non-small-cell lung cancer. Oncogene 2009;28:S32-7.

17. Hirsch FR, Varella-Garcia M, McCoy J, et al. Increased epidermal growth factor receptor gene copy number detected by fluorescence in situ hybridization associates with increased sensitivity to gefitinib in patients with bronchioloalveolar carcinoma subtypes: a Southwest Oncology Group Study. J Clin Oncol 2005; 23:6838-45.

18. Sequist LV, Bell DW, Lynch TJ, Haber DA. Molecular predictors of response to epidermal growth factor receptor antagonists in non-small-cell lung cancer. J Clin Oncol 2007;25:587-95.

19. Gupta R, Dastane AM, McKenna R Jr, Marchevsky AM. The predictive value of epidermal growth factor receptor tests in patients with pulmonary adenocarcinoma: review of current "best evidence" with meta-analysis. Hum Pathol 2009;40: 356-65.

20. Takano T, Ohe Y, Sakamoto H, et al. Epidermal growth factor receptor gene mutations and increased copy numbers predict gefitinib sensitivity in patients with recurrent non-small-cell lung cancer. J Clin Oncol 2005;23:6829-37.

21. Bell DW, Lynch TJ, Haserlat SM, et al. Epidermal growth factor receptor mutations and gene amplification in nonsmall-cell lung cancer: molecular analysis of the IDEAL/INTACT gefitinib trials. J Clin Oncol 2005;23:8081-92.

22. Sone T, Kasahara K, Kimura $\mathrm{H}$, et al. Comparative analysis of epidermal growth factor receptor mutations and gene amplification as predictors of gefitinib efficacy in Japanese patients with nonsmall cell lung cancer. Cancer 2007;109:1836-44.

23. Cappuzzo F, Ligorio C, Jänne PA, et al. Prospective study of gefitinib in epidermal growth factor receptor fluorescence in situ hybridization-positive/phosphoAkt-positive or never smoker patients with advanced non-small-cell lung cancer: the ONCOBELL trial. J Clin Oncol 2007; 25:2248-55.

24. Hirsch FR, Varella-Garcia M, Cappuzzo F, et al. Combination of EGFR gene copy number and protein expression predicts outcome for advanced non-small-cell lung cancer patients treated with gefitinib. Ann Oncol 2007;18:752-60.

25. Ahn MJ, Park BB, Ahn JS, et al. Are there any ethnic differences in molecular predictors of erlotinib efficacy in advanced non-small cell lung cancer? Clin Cancer Res 2008;14:3860-6.

26. Dongiovanni D, Daniele L, Barone C, et al. Gefitinib (ZD1839): therapy in selected patients with non-small cell lung cancer (NSCLC)? Lung Cancer 2008;61:7381.

27. Schneider CP, Heigener D, Schott-vonRömer K, et al. Epidermal growth factor receptor-related tumor markers and clinical outcomes with erlotinib in non-small cell lung cancer: an analysis of patients from german centers in the TRUST study. J Thorac Oncol 2008;3:1446-53.

28. Crinò L, Cappuzzo $\mathrm{F}$, Zatloukal $\mathrm{P}$, et al. Gefitinib versus vinorelbine in chemotherapy-naive elderly patients with advanced non-small-cell lung cancer (INVITE): a randomized, phase II study. J Clin Oncol 2008;26:4253-60.

29. Paez JG, Jänne PA, Lee JC, et al. EGFR mutations in lung cancer: correlation with clinical response to gefitinib therapy. Science 2004;304:1497-500.

30. Lynch TJ, Bell DW, Sordella R, et al. Activating mutations in the epidermal growth factor receptor underlying responsiveness of non-small-cell lung cancer to gefitinib. N Engl J Med 2004;350:2129-39.

31. Pao W, Miller V, Zakowski M, et al. EGF receptor gene mutations are common in lung cancers from "never smokers" and are associated with sensitivity of tumors to gefitinib and erlotinib. Proc Natl Acad Sci USA 2004;101:13306-11.

32. Pao W, Miller VA. Epidermal growth factor receptor mutations, small-molecule kinase inhibitors, and non-small-cell lung cancer: current knowledge and future directions. J Clin Oncol 2005;23:2556-68.

33. Riely GJ, Politi KA, Miller VA, Pao W. Update on epidermal growth factor receptor mutations in non-small cell lung cancer. Clin Cancer Res 2006;12:7232-41.

34. Shigematsu H, Lin L, Takahashi T, et al. Clinical and biological features associated with epidermal growth factor receptor gene mutations in lung cancers. J Natl Cancer Inst 2005;97:339-46.

35. Marchetti A, Martella C, Felicioni L, et al.
EGFR mutations in non-small-cell lung cancer: analysis of a large series of cases and development of a rapid and sensitive method for diagnostic screening with potential implications on pharmacologic treatment. J Clin Oncol 2005;23:857-65.

36. Sharma SV, Bell DW, Settleman J, Haber DA. Epidermal growth factor receptor mutations in lung cancer. Nat Rev Cancer 2007;7:169-81.

37. Dahabreh IJ, Linardou H, Siannis F, et al. Somatic EGFR mutation and gene copy gain as predictive biomarkers for response to tyrosine kinase inhibitors in non-small cell lung cancer. Clin Cancer Res 2010;16:291-303.

38. Sordella R, Bell DW, Haber DA, Settleman J. Gefitinib-sensitizing EGFR mutations in lung cancer activate anti-apoptotic pathways. Science 2004;305:1163-7.

39. Tracy S, Mukohara T, Hansen M, et al. Gefitinib induces apoptosis in the EGFRL858R non-small-cell lung cancer cell line H3255. Cancer Res 2004;64:72414.

40. Mulloy R, Ferrand A, Kim Y, et al. Epidermal growth factor receptor mutants from human lung cancers exhibit enhanced catalytic activity and increased sensitivity to gefitinib. Cancer Res 2007; 67:2325-30.

41. Greulich H, Chen TH, Feng W, et al. Oncogenic transformation by inhibitorsensitive and -resistant EGFR mutants. PLoS Med 2005;2:e313.

42. Jiang J, Greulich H, Jänne PA, et al. Epidermal growth factor-independent transformation of $\mathrm{Ba} / \mathrm{F} 3$ cells with cancerderived epidermal growth factor receptor mutants induces gefitinib-sensitive cell cycle progression. Cancer Res 2005;65: 8968-74.

43. Taron M, Ichinose $\mathrm{Y}$, Rosell $\mathrm{R}$, et al. Activating mutations in the tyrosine kinase domain of the epidermal growth factor receptor are associated with improved survival in gefitinib-treated chemorefractory lung adenocarcinomas. Clin Cancer Res 2005;11:5878-85.

44. Kobayashi S, Boggon TJ, Dayaram T, et al. EGFR mutation and resistance of nonsmall-cell lung cancer to gefitinib. N Engl J Med 2005;352:786-92.

45. Pao W, Miller VA, Politi KA, et al. Acquired resistance of lung adenocarcinomas to gefitinib or erlotinib is associated with a second mutation in the EGFR kinase domain. PLoS Med 2005;2:e73.

46. Kosaka T, Yatabe Y, Endoh H, et al. Analysis of epidermal growth factor receptor gene mutation in patients with non-small cell lung cancer and acquired resistance to gefitinib. Clin Cancer Res 2006;12:5764-9. 
47. Maheswaran S, Sequist LV, Nagrath S, et al. Detection of mutations in EGFR in circulating lung-cancer cells. N Engl J Med 2008;359:366-77.

48. Zhou W, Ercan D, Chen L, et al. Novel mutant-selective EGFR kinase inhibitors against EGFR T790M. Nature 2009;462: 1070-4.

49. Sasaki H, Endo K, Takada M, et al. EGFR exon 20 insertion mutation in Japanese lung cancer. Lung Cancer 2007;58:324-8.

50. Balak MN, Gong Y, Riely GJ, et al. Novel D761Y and common secondary T790M mutations in epidermal growth factor receptor-mutant lung adenocarcinomas with acquired resistance to kinase inhibitors. Clin Cancer Res 2006;12:6494501.

51. Rodenhuis S, Slebos RJ, Boot AJ, et al. Incidence and possible clinical significance of K-ras oncogene activation in adenocarcinoma of the human lung. Cancer Res 1988;48:5738-41.

52. Suzuki Y, Orita M, Shiraishi M, et al. Detection of ras gene mutations in human lung cancers by single-strand conformation polymorphism analysis of polymerase chain reaction products. Oncogene 1990;5:1037-43.

53. Ahrendt SA, Decker PA, Alawi EA, et al. Cigarette smoking is strongly associated with mutation of the K-ras gene in patients with primary adenocarcinoma of the lung. Cancer 2001;92:1525-30.

54. Pao W, Wang TY, Riely GJ, et al. KRAS mutations and primary resistance of lung adenocarcinomas to gefitinib or erlotinib. PLoS Med 2005;2:e17.

55. Eberhard DA, Johnson BE, Amler LC, et al. Mutations in the epidermal growth factor receptor and in KRAS are predictive and prognostic indicators in patients with non-small-cell lung cancer treated with chemotherapy alone and in combination with erlotinib. J Clin Oncol 2005;23:59009.

56. Linardou H, Dahabreh IJ, Kanaloupiti D, et al. Assessment of somatic k-RAS mutations as a mechanism associated with resistance to EGFR-targeted agents: a systematic review and meta-analysis of studies in advanced non-small-cell lung cancer and metastatic colorectal cancer. Lancet Oncol 2008;9:962-72.

57. Jackman DM, Miller VA, Cioffredi LA, et al. Impact of epidermal growth factor receptor and KRAS mutations on clinical outcomes in previously untreated nonsmall cell lung cancer patients: results of an online tumor registry of clinical trials. Clin Cancer Res 2009;15:5267-73.

58. Birchmeier C, Birchmeier W, Gherardi E, Vande Woude GF. Met, metastasis, motility and more. Nat Rev Mol Cell Biol 2003;4:
915-25.

59. Cappuzzo F, Marchetti A, Skokan M, et al. Increased MET gene copy number negatively affects survival of surgically resected non-small-cell lung cancer patients. J Clin Oncol 2009;27:1667-74.

60. Go H, Jeon YK, Park HJ, et al. High MET gene copy number leads to shorter survival in patients with non-small cell lung cancer. J Thorac Oncol 2010;5:305-13.

61. Yang CH, Yu CJ, Shih JY, et al. Specific EGFR mutations predict treatment outcome of stage IIIB/IV patients with chemotherapy-naive non-small-cell lung cancer receiving first-line gefitinib monotherapy. J Clin Oncol 2008;26:274553.

62. Cappuzzo F, Jänne PA, Skokan M, et al. MET increased gene copy number and primary resistance to gefitinib therapy in non-small-cell lung cancer patients. Ann Oncol 2009;20:298-304.

63. Engelman JA, Zejnullahu K, Mitsudomi T, et al. MET amplification leads to gefitinib resistance in lung cancer by activating ERBB3 signaling. Science 2007;316:103943.

64. Hammerman PS, Jänne PA, Johnson BE. Resistance to Epidermal Growth Factor Receptor Tyrosine Kinase Inhibitors in Non-Small Cell Lung Cancer. Clin Cancer Res 2009;15:7502-9.

65. Bean J, Brennan C, Shih JY, et al. MET amplification occurs with or without T790M mutations in EGFR mutant lung tumors with acquired resistance to gefitinib or erlotinib. Proc Natl Acad Sci USA 2007;104:20932-7.[FullText] 66.

Chiarle R, Voena C, Ambrogio C, et al. The anaplastic lymphoma kinase in the pathogenesis of cancer. Nat Rev Cancer 2008;8:11-23.

67. Soda M, Choi YL, Enomoto M, et al. Identification of the transforming EML4ALK fusion gene in non-small-cell lung cancer. Nature 2007;448:561-6.

68. Soda M, Takada S, Takeuchi K, et al. A mouse model for EML4-ALK-positive lung cancer. Proc Natl Acad Sci USA 2008;105: 19893-7.

69. Shaw AT, Yeap BY, Mino-Kenudson M, et al. Clinical features and outcome of patients with non-small-cell lung cancer who harbor EML4-ALK. J Clin Oncol 2009; 27:4247-53.

70. Solomon B, Varella-Garcia M, Camidge DR. ALK gene rearrangements: a new therapeutic target in a molecularly defined subset of non-small cell lung cancer. J Thorac Oncol 2009;4:1450-4.

71. Vivanco I, Sawyers CL. The phosphatidylinositol 3-Kinase AKT pathway in human cancer. Nat Rev Cancer 2002;2:489-501.

72. Brognard J, Clark AS, Ni Y, et al. Akt/pro- tein kinase B is constitutively active in non-small cell lung cancer cells and promotes cellular survival and resistance to chemotherapy and radiation. Cancer Res 2001;61:3986-97.

73. Cantley LC, Neel BG. New insights into tumor suppression: PTEN suppresses tumor formation by restraining the phosphoinositide 3-kinase/AKT pathway. Proc Natl Acad Sci USA 1999;96:4240-5.

74. Cappuzzo F, Magrini E, Ceresoli GL, et al. Akt phosphorylation and gefitinib efficacy in patients with advanced non-small-cell lung cancer. J Natl Cancer Inst 2004;96: 1133-41.

75. Sos ML, Koker M, Weir BA, et al. PTEN loss contributes to erlotinib resistance in EGFR-mutant lung cancer by activation of Akt and EGFR. Cancer Res 2009;69:325661.

76. Kumar MS, Lu J, Mercer KL, et al. Impaired microRNA processing enhances cellular transformation and tumorigenesis. Nat Genet 2007;39:673-7.

77. Eder M, Scherr M. MicroRNA and lung cancer. N Engl J Med 2005;352:2446-8.

78. Fabbri M, Croce CM, Calin GA. MicroRNAs. Cancer J 2008;14:1-6.

79. Seike M, Goto A, Okano T, et al. MiR-21 is an EGFR-regulated anti-apoptotic factor in lung cancer in never-smokers. Proc Natl Acad Sci USA 2009;106:12085-90.

80. Weiss GJ, Bemis LT, Nakajima E, et al. EGFR regulation by microRNA in lung cancer: correlation with clinical response and survival to gefitinib and EGFR expression in cell lines. Ann Oncol 2008;19: 1053-9.

81. Balko JM, Potti A, Saunders C, et al. Gene expression patterns that predict sensitivity to epidermal growth factor receptor tyrosine kinase inhibitors in lung cancer cell lines and human lung tumors. BMC Genomics 2006;7:289.

82. Carbone DP, Salmon JS, Billheimer D, et al. VeriStrat((R)) classifier for survival and time to progression in non-small cell lung cancer (NSCLC) patients treated with erlotinib and bevacizumab. Lung Cancer 2009. [Epub ahead of print]

83. Chung $\mathrm{CH}$, Seeley EH, Roder H, et al. Detection of tumor epidermal growth factor receptor pathway dependence by serum mass spectrometry in cancer patients. Cancer Epidemiol Biomarkers Prev 2010:19:358-65.

84. Santini D, Loupakis F, Vincenzi B, et al. High concordance of KRAS status between primary colorectal tumors and related metastatic sites: implications for clinical practice. Oncologist 2008;13: 1270-5.

85. Italiano A, Hostein I, Soubeyran I, et al. KRAS and BRAF Mutational Status in 
Primary Colorectal Tumors and Related Metastatic Sites: Biological and Clinical Implications. Ann Surg Oncol 2010;17: 1429-34.

86. Italiano A, Vandenbos FB, Otto J, et al. Comparison of the epidermal growth factor receptor gene and protein in primary non-small-cell-lung cancer and metastatic sites: implications for treatment with EGFR-inhibitors. Ann Oncol 2006;17:9815.

87. Sun M, Behrens C, Feng L, et al. HER family receptor abnormalities in lung cancer brain metastases and corresponding primary tumors. Clin Cancer Res 2009;15: 4829-37.

88. Daniele L, Cassoni P, Bacillo E, et al. Epidermal growth factor receptor gene in primary tumor and metastatic sites from non-small cell lung cancer. J Thorac Oncol 2009;4:684-8.

89. Scartozzi M, Bearzi I, Berardi R, et al. Epidermal growth factor receptor (EGFR) downstream signalling pathway in primary colorectal tumours and related metastatic sites: optimising EGFR-targeted treatment options. $\mathrm{Br} \mathrm{J}$ Cancer 2007;97:92-7.

90. Gomez-Roca C, Raynaud CM, PenaultLlorca F, et al. Differential Expression of Biomarkers in Primary Non-small Cell Lung Cancer and Metastatic Sites. J Thorac Oncol 2009;4:1212-20.

91. Kalikaki A, Koutsopoulos A, Trypaki M, et al. Comparison of EGFR and K-RAS gene status between primary tumours and corresponding metastases in NSCLC. Br J Cancer 2008;99:923-9.

92. Park S, Holmes-Tisch AJ, Cho EY, et al. Discordance of molecular biomarkers associated with epidermal growth factor receptor pathway between primary tumors and lymph node metastasis in non-small cell lung cancer. J Thorac Oncol 2009;4:809-15.

93. Gow CH, Chang YL, Hsu YC, et al. Comparison of epidermal growth factor receptor mutations between primary and corresponding metastatic tumors in tyrosine kinase inhibitor-naive non-small-cell lung cancer. Ann Oncol 2009;20:696-702.

94. Bozzetti C, Tiseo M, Lagrasta C, et al.
Comparison between epidermal growth factor receptor (EGFR) gene expression in primary non-small cell lung cancer (NSCLC) and in fine-needle aspirates from distant metastatic sites. J Thorac Oncol 2008;3:18-22.

95. Schmid K, Oehl N, Wrba F, et al. EGFR/KRAS/BRAF mutations in primary lung adenocarcinomas and corresponding locoregional lymph node metastases. Clin Cancer Res 2009;15:4554-60.

96. Monaco SE, Nikiforova MN, Cieply K, et al. A comparison of EGFR and KRAS status in primary lung carcinoma and matched metastases. Hum Pathol 2010; 41:94-102.

97. Gallegos Ruiz MI, Floor K, Rijmen F, et al. EGFR and K-ras mutation analysis in nonsmall cell lung cancer: comparison of paraffin embedded versus frozen specimens. Cell Oncol 2007;29:257-64.

98. Chen JT, Lane MA, Clark DP. Inhibitors of the polymerase chain reaction in Papanicolaou stain. Removal with a simple destaining procedure. Acta Cytol 1996; 40:873-7.

99. Smith GD, Chadwick BE, Willmore-Payne C, Bentz JS. Detection of epidermal growth factor receptor gene mutations in cytology specimens from patients with non-small cell lung cancer utilising highresolution melting amplicon analysis. $\mathrm{J}$ Clin Pathol 2008;61:487-93.

100. Smouse JH, Cibas ES, Jänne PA, et al. EGFR mutations are detected comparably in cytologic and surgical pathology specimens of nonsmall cell lung cancer. Cancer Cytopathol 2009;117:67-72.

101. Yasuda I, Kato T, Asano F, et al. Mediastinal Lymph Node Staging in Potentially Resectable Non-Small Cell Lung Cancer: A Prospective Comparison of CT and EUS/EUS-FNA. Respiration 2009;78:423-31.

102.Sozzi G, Conte D, Leon M, et al. Quantification of free circulating DNA as a diagnostic marker in lung cancer. J Clin Oncol 2003;21:3902-8.

103. Ulivi P, Mercatali L, Zoli W, et al. Serum free DNA and COX-2 mRNA expression in peripheral blood for lung cancer detection. Thorax 2008;63:843-4.
104. Kimura H, Kasahara K, Kawaishi M, et al. Detection of epidermal growth factor receptor mutations in serum as a predictor of the response to gefitinib in patients with non-small-cell lung cancer. Clin Cancer Res 2006;12:3915-21.

105. Kimura H, Suminoe M, Kasahara K, et al. Evaluation of epidermal growth factor receptor mutation status in serum DNA as a predictor of response to gefitinib (IRESSA). Br J Cancer 2007;97:778-84.

106. Yung TK, Chan KC, Mok TS, et al. Singlemolecule detection of epidermal growth factor receptor mutations in plasma by microfluidics digital PCR in non-small cell lung cancer patients. Clin Cancer Res 2009;15:2076-84.

107. Kuang Y, Rogers A, Yeap BY, et al. Noninvasive detection of EGFR T790M in gefitinib or erlotinib resistant non-small cell lung cancer. Clin Cancer Res 2009; 15:2630-6.

108. He C, Liu M, Zhou C, et al. Detection of epidermal growth factor receptor mutations in plasma by mutant-enriched PCR assay for prediction of the response to gefitinib in patients with non-small-cell lung cancer. Int J Cancer 2009;125:23939.

109. Bai H, Mao L, Wang HS, et al. Epidermal growth factor receptor mutations in plasma DNA samples predict tumor response in Chinese patients with stages IIIB to IV non-small-cell lung cancer. J Clin Oncol 2009;27:2653-9.

110. Mack PC, Holland WS, Burich RA, et al. EGFR mutations detected in plasma are associated with patient outcomes in erlotinib plus docetaxel-treated non-small cell lung cancer. J Thorac Oncol 2009;4: 1466-72.

111. Rosell R, Moran T, Queralt C, et al. Screening for epidermal growth factor receptor mutations in lung cancer. $\mathrm{N}$ Engl J Med 2009;361:958-67.

112. Chung CH, Seeley EH, Roder H, et al. Detection of tumor epidermal growth factor receptor pathway dependence by serum mass spectrometry in cancer patients. Cancer Epidemiol Biomarkers Prev 2010;19:358-65. 